\title{
Article
}

\section{Sir Henry Hallet Dale}

\author{
Wickens, Andrew
}

Available at http://clok.uclan.ac.uk/29907/

Wickens, Andrew (2019) Sir Henry Hallet Dale. Resonance, 24 (8). pp. 833845. ISSN 0971-8044

It is advisable to refer to the publisher's version if you intend to cite from the work.

http://dx.doi.org/10.1007/s12045-019-0847-8

For more information about UCLan's research in this area go to

http://www.uclan.ac.uk/researchgroups/ and search for < name of research Group>.

For information about Research generally at UCLan please go to http://www.uclan.ac.uk/research/

All outputs in CLoK are protected by Intellectual Property Rights law, including Copyright law. Copyright, IPR and Moral Rights for the works on this site are retained by the individual authors and/or other copyright owners. Terms and conditions for use of this material are defined in the policies page.

\section{CLoK}

Central Lancashire online Knowledge www.clok.uclan.ac.uk

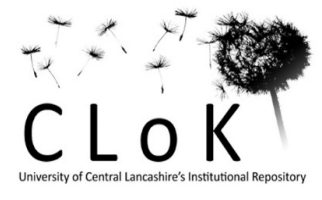




\section{Sir Henry Hallet Dale*}

\section{(1875-1968)}

\section{Andrew Wickens}

Sir Henry Hallet Dale can undisputedly be accoladed as one of the greatest British pharmacologists of the twentieth century. His work was pivotal in laying down the principles of chemical neurotransmission. This article gives some account of Dale's life and his most important discoveries, including the identification of acetylcholine as a neurotransmitter in the autonomic and somatic nervous systems.

\section{Introduction}

The concept of chemical neurotransmission at the synapse is one of the fundamental keystones on which neuroscience is built. Indeed, without the knowledge of chemical neurotransmission, it would be impossible to understand how the nervous system, including the brain, operates. Sir Henry Dale's identification of acetylcholine as a neurotransmitter at several sites in the peripheral nervous system ${ }^{1}$, including the synapse between the preganglionic and post-ganglionic fibres of the sympathetic system ${ }^{2}$; the post-ganglionic parasympathetic synapse; and the neuromuscular junction ${ }^{3}$, were groundbreaking advances in proving that neurons communicate with each other using chemical messengers ${ }^{4}$.

In addition, Dale recognised that acetylcholine had both muscarinic and nicotinic-like actions depending on its site of action. Further discoveries made by Dale included the role of histamine, which he showed was a natural constituent of the body and involved in anaphylactic shock; the pituitary hormone oxytocin and the first adrenergic blocking agents now being used to treat a

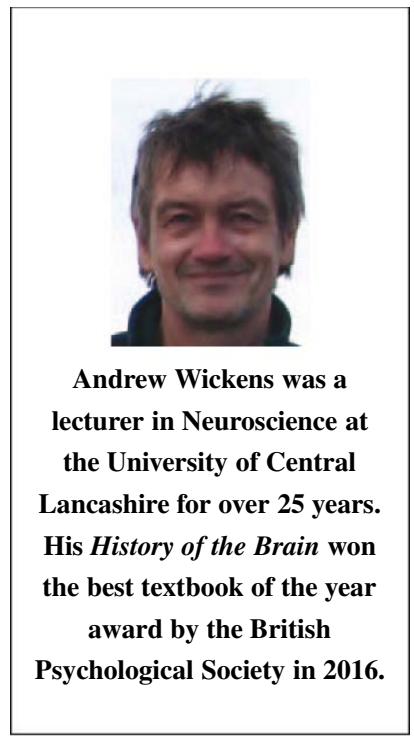

$1_{\text {The peripheral nervous sys- }}$ tem is composed of (1) the autonomic nervous system which has sympathetic and parasympathetic branches, and (2) the somatic nervous system which controls the skeletal muscles.

\section{Keywords}

Dale, acetylcholine, histamine, receptors, neurotransmission, autonomic nervous system, somatic nervous system. 
${ }^{2}$ Both the sympathetic and parasympathetic systems are composed of a chain of two motor neurons. The preganglionic fibres originate in the spinal cord and these synapse onto postganglionic fibres which provide the final output to the organs of the body.

${ }^{3}$ The somatic nervous system has only one synapse - at the junction of the motor nerve fibre and muscle (neuromuscular junction or NMJ).

${ }^{4}$ Electrical synapses are also known to exist but are much rarer than chemical ones.

${ }^{5}$ Langley coined the terms 'autonomic', 'sympathetic', and 'parasympathetic'. He was also the first, in 1905, to suggest that many drugs worked on pharmacological receptors. range of disorders. Perhaps, not surprisingly, these scientific achievements tend to overshadow many of Dale's other contributions to the development of pharmacology, including his role as a research director and scientific politician. Indeed, his influence is still strongly felt today - for both his contribution to promoting an international pharmacologic standardisation, as well as for coining a large number of terms that remain in common usage including 'sympathomimetic', 'cholinergic' and 'adrenergic'. Dale's outstanding deeds were recognised by numerous degrees from more than twenty universities. In addition, he was a recipient of many other distinctions, including the presidency of the Royal Society, a knighthood and a Nobel Prize.

\section{Early Life and Studies}

Dale was born in London (1875), the third son of seven children, into a relatively prosperous middle-class family (his father, Charles James Dale, was an active Methodist and manager of a Derbyshire stoneware firm). After being educated at small public schools, Dale won a scholarship to the Leys School in Cambridge in 1891 - an institution strongly focussed on getting its Methodist students into Cambridge University and its colleges. The school was also unusual for its promotion of science, and it was here that Dale would make his first forays into biological experimentation using frog muscle-nerve preparations and simple histological techniques. After winning a scholarship to enter Trinity College in 1894 to study natural sciences, Dale came under the influence of John Langley ${ }^{5}$ and Walter Gaskell, leading to his first scientific paper in 1900. Leaving Cambridge in the same year to finish his medical training in 1904 at St. Bartholomew's Hospital, London, Dale would spend some of his time working at University College with Ernest Starling and William Bayliss. It was here that Dale first met Otto Loewi, who became a lifelong friend and co-recipient of the Nobel Prize.

In his semi-autobiographical Adventures in Physiology (1953), Dale claims he was faced with a bleak academic prospect after 


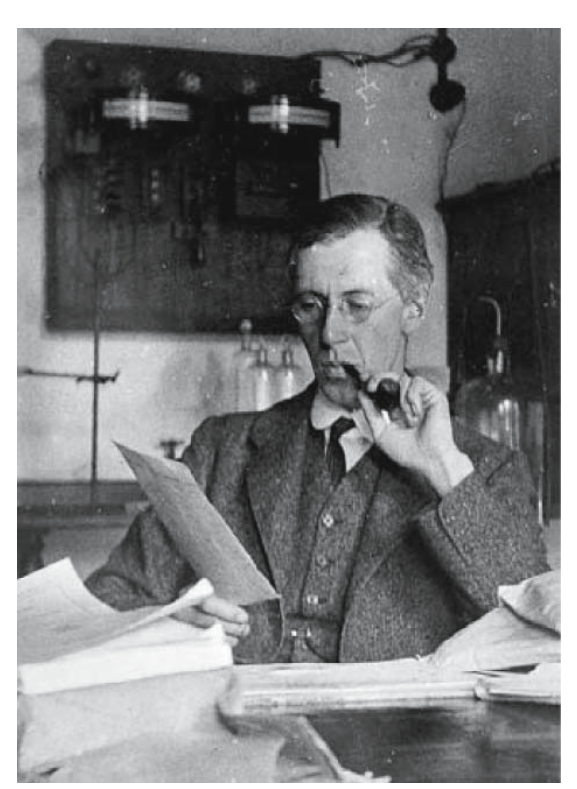

completing his medical training in 1904, which was also the year of his marriage to his childhood sweetheart and cousin, Ellen Harriet Hallet. With the need for financial stability in mind, Dale accepted appointment as a pharmacologist at the newly established Wellcome Physiological Research Laboratories in London. This was an unusual choice since the Wellcome Institute was a non-profiting concern, created by the American, Henry Wellcome (later Sir) aimed at scientific advancement for the benefit of all. In fact, this objective had already been met when Wellcome was able to produce an economically viable antitoxin for diphtheria in 1894. It was also an appointment that went against the advice of his university friends who feared it would compromise Dale's independence as a researcher. However, the Wellcome Institute offered a secure income with the chance of career advancement, and Dale was to take full advantage of this situation by becoming its Director in 1906.

When Dale started work in his new job, he was asked to examine the chemical constituents of a parasitic fungus Claviceps purpurea, otherwise known as ergot, which had been known to infect rye and other cereal grasses in the medieval times. This had led to epidemic outbreaks called St. Anthony's fire that was associ-
Figure 1. A photograph of Henry Dale taken in 1918 at the Lister Institute for Preventive Medicine. Source: Wellcome Library, London.

Dale first met Otto Loewi in 1902 at $\mathrm{St}$ Bartholomew's Hospital, London (where a plaque in the pathology museum marks the site where Sherlock Holmes and Doctor Watson first met). 
At first Dale was "not at all attracted by the prospect" of examining the chemical properties of ergot.

${ }^{6}$ Alpha-adrenergic blocking agents act to dilate the blood vessels and are used to lower blood pressure.

Sir Henry Dale was unique among biomedical scientists since he never held a primary academic post at a university. ated with convulsions, hallucinations and intense burning sensations in its victims. Later, in the eighteenth century, ergot was found to cause constriction of blood vessels and uterus, resulting in its adoption by midwives, who used it to induce abortions or stop bleeding after childbirth. Dale admitted he was "not at all attracted by the prospect" of making his first career move into examining "the ergot morass". Yet, Wellcome's suggestion turned out to be a fortuitous one. As Dale began to examine ergot, he realised it was a treasure trove of active pharmacological substances, many of which were isolated by his colleague and brilliant young chemist George Barger.

Dale's first breakthrough with ergot came by a stroke of good fortune. One day he was asked to test an extract from the adrenal glands to see if it contained adrenaline. He tested the extract by injecting it into a cat pre-treated with ergot and found that the animal's adrenal-induced blood pressure did not increase as expected. Clearly, there was something in the ergot inhibiting the effects of the adrenal extract. Indeed, this turned out to be a substance called ergotoxine, which blocked the constricting effects of adrenaline on the smooth muscle of blood vessels. Dale had not only discovered the first alpha-adrenergic blocking agents, which are now used to treat a range of medical conditions ${ }^{6}$, but he also realised that receptors for adrenaline must exist on the arterioles which he called 'adrenoreceptors'. This discovery also encouraged Dale to examine more closely the role of noradrenaline - a substance then commercially available. Dale soon realised that noradrenaline mimicked the effects of sympathetic nervous stimulation better than adrenaline itself. Although he did not go as far as to suggest that noradrenaline was acting as a neurotransmitter in the sympathetic nervous system, this would eventually be shown to be the case in the 1940s, largely as a result of research by Ulf von Euler in Sweden.

In 1910, Dale and Barger identified another chemical in ergot which caused the uterine smooth muscle and bronchioles to constrict. This substance also caused a fall in blood pressure, with injections into animals producing many symptoms of anaphylac- 
tic shock - a severe and potentially life-threatening response often triggered by an allergic reaction. In fact, they had discovered histamine, shown a year later by Dale to be a naturally occurring chemical in the body, after he isolated it from the walls of the intestine. Over the next decade, Dale would show that histamine is distributed throughout the body and is released by biological tissues in response to injury, where it supported the immune response by allowing capillary dilation and 'leakage'. This discovery was of great importance in surgery, especially during World War 1, when the control of anaphylactic shock was necessary to avoid serious and fatal complications. Later, in the 1940s, histamine was also found in the brain's nervous tissue and identified as a neurotransmitter in the 1960s.

\section{The Discovery of Acetylcholine}

Undoubtedly, Dale's most important discovery was establishing the role of acetylcholine in autonomic and somatic nervous function. This story first began in 1913 when Dale was asked to test a routine extract of ergot. Normally, ergot would have produced a modest rise in arterial blood pressure when injected into an anaesthetized cat - although on this occasion, the extract had the opposite effect. At first, Dale thought he had inadvertently injected a life-threatening air bubble into the animal, but with repeated testing realised this was not the case. Instead, Dale began to suspect that ergot might contain muscarine. This chemical, first extracted from the iconic red and white spotted fly agaric mushroom (Amanita muscaria), was of great interest to pharmacologists since it produced a number of effects including bradycardia, hypotension and pupil constriction. All of these actions were ones that closely mimicked the action of the parasympathetic nervous system. However, after working with colleague Arthur Ewins, Dale realised that the depressor substance in ergot was actually acetylcholine. This chemical was already known to physiologists since choline had been found in the adrenal glands and shown to reduce blood pressure, an effect that had led Reid Hunt to synthesise a number of choline derivatives - one of which was
Undoubtedly, Dale's most important discovery was establishing the role of acetylcholine in autonomic and somatic nervous function. 
In 1914, Dale realised that the effects of acetylcholine could be mimicked by two different types of substance - muscarine and nicotine. acetylcholine. Remarkably, this chemical was a hundred thousand times more active than choline in its biological effects, suggesting a pharmacological role. The implication, although Dale was careful not to endorse it at the time, was that acetylcholine acted as a neurotransmitter in the parasympathetic system; a controversial idea since few pharmacologists endorsed chemical neurotransmission, and acetylcholine had yet to be found in the body.

Although muscarine and acetylcholine had similar physiological effects in many areas of the body, there were notable exceptions. One was the neuromuscular junction where only acetylcholine caused muscle contraction. This site also showed another interesting characteristic since the effects of acetylcholine were mimicked here by nicotine. Moreover, both acetylcholine and nicotine were blocked by curare. In contrast, the action of muscarine on the parasympathetic system was blocked by the alkaloid atropine. Dale offered an explanation for these results in 1914 when he proposed the existence of two types of cholinergic receptors with different chemical affinities: muscarinic and nicotinic. This still did not prove the concept of neurotransmission, although, in hindsight, it was an important step in its development.

\section{Dale and the First World War}

In 1914, Dale left his post at Wellcome to join the newly created Medical Research Committee (later the National Institute for Medical Research) where he became the Head of the Department of Biochemistry and Pharmacology. Located in an old tuberculosis hospital at Mount Vernon, in Hampstead, north London, MRC was an organisation with large funds provided by the British government for medical research. However, Dale's work on acetylcholine would be put on hold due to the outbreak of the First World War. With his research priorities now directed to wartime concerns, Dale began examining traumatic or secondary wound shock, which could prove fatal among battle casualties. Dale knew this was in large part due to the body's release of histamine which greatly diminished the flow of blood to the left side 


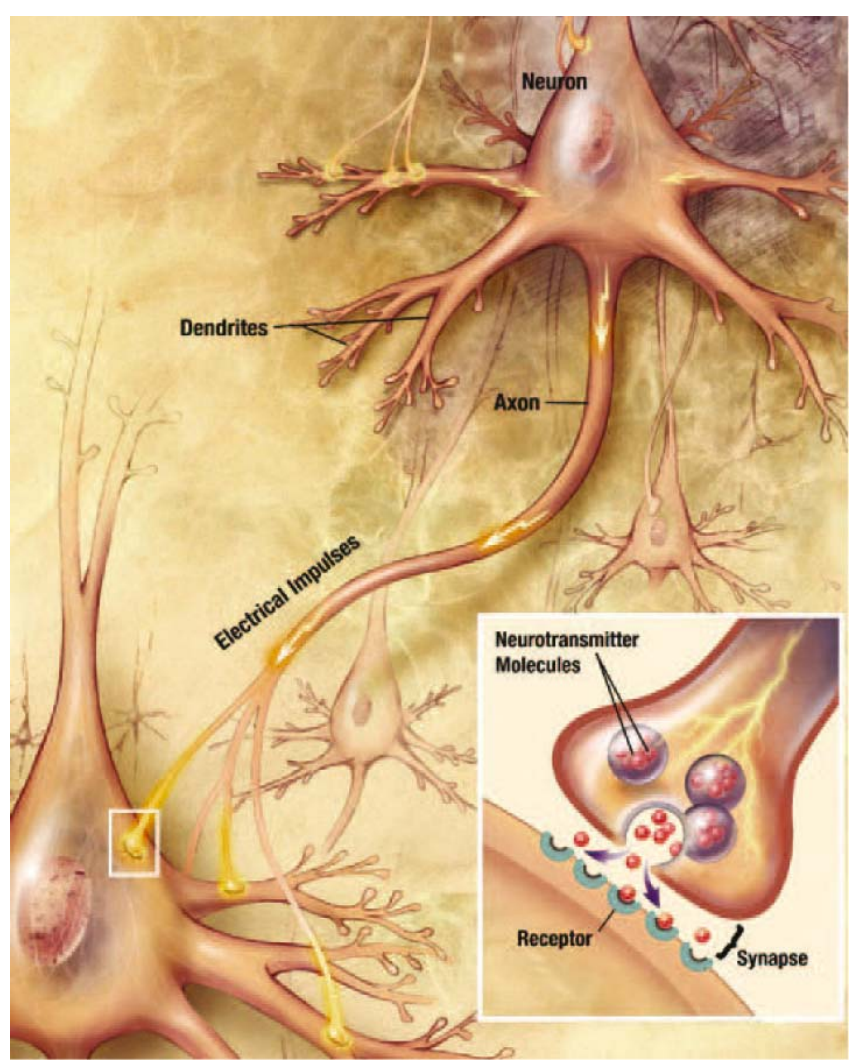

of the heart, and he found an effective remedy using plasma transfusion to increase the circulating blood volume. Dale also began to undertake tests on drugs produced by the British and French manufacturers to replace the German pharmaceuticals, including Salvarsan for the treatment of syphilis, which had become a serious problem amongst British soldiers. However, Dale soon realised that this task was problematic since the medical substances he was given to test often had different potencies and safety limits. Consequently, he began to promote and insist on more stringent regulation. Many of his recommendations for improvements in drug standardisation would later become commonplace and adopted internationally.
Figure 2. Chemical synaptic transmission. Source: Wikimedia Commons (created by the user Looie496, US National Institutes of Health, National Institute on Aging. 


\section{Experimental Proof for Chemical Neurotransmission}

On Easter Sunday, 1920,

Otto Loewi performed what is arguably the most famous experiment in pharmacology.
Although the possibility of chemical neurotransmission at the synapse had first been raised in the late nineteenth century, and the concept of chemical receptors given credence in 1905 by Cambridge physiologist Thomas Elliot, both ideas were contentious. For many, it was much more likely that synaptic communication was electrical than chemical. Indeed, Dale, for one, was not prepared to speculate on the possibility of chemical neurotransmitters when the evidence remained so highly tentative. The impasse required a definitive demonstration of chemical neurotransmission, and this would be provided by Dale's friend Otto Loewi in 1920. A German of Jewish extraction, Loewi undertook an experiment which has become part of pharmacological folklore. Claiming to have woken from a dream on the night of Easter Saturday, 1920, where an idea for an experiment had come to him, Loewi scribbled down his thoughts, only to find he was unable to decipher them in the next morning. The following night, Loewi experienced the same dream, and this time took no chances. He cycled to his laboratory and performed the experiment which took less than two hours. Upon seeing the results the next morning, Loewi's research assistant is reputed to have said that it would win him the Nobel Prize. It was an assessment that proved true.

The experiment was simple. Loewi placed the heart of a frog still attached to its parasympathetic (vagus) and sympathetic nerves in a saline chamber. He then stimulated the vagus nerve, which he knew would cause the heartbeat to slow down. It was at this point that Loewi did something new: He removed some of the solution from the chamber and applied it to another heart whose vagus nerve had been removed (deafferented). The result was that the beat of the deafferented heart also began to slow. In fact, this solution inhibited the heart as potently as vagal stimulation itself. The only feasible explanation was that the first heart had secreted a chemical (or what Loewi called a neurohumoral substance) into the saline, which then acted on the second heart. To confirm this, Loewi stimulated the sympathetic branch of the first heart causing it to beat faster. Again, he extracted the bathing fluid and applied 
it to the second heart. This time, the heartbeat increased. Loewi called the inhibiting agent from the vagus nerve 'vagusstoff', and the accelerating agent 'acceleransstoff'.

In the years after his experiment, Loewi attempted to identify the chemical nature of these two substances. Although Loewi suspected that the inhibitory agent was acetylcholine and the excitatory agent an adrenaline-like substance, it would take many more experiments before the answers became clear. Nonetheless, Loewi would be proven correct with acetylcholine being identified as the vagal depressor substance, a theory he helped to prove by finding small traces of cholinesterase in the heart tissue in 1930. Later, noradrenaline would be recognised as the accelerator substance - the same neurochemical that Dale had shown earlier to mimic the effects of sympathetic stimulation.

\section{Confirming Acetylcholine as a Neurotransmitter}

By the late 1920s, evidence had accumulated to convince many that acetylcholine was a neurotransmitter - at least in the autonomic nervous system. However, before acetylcholine could be fully established as having this role, it would have to be identified as a natural chemical in the body. This was no easy task. If acetylcholine was being released from the nerve endings, then the amounts were minuscule and most probably broken down almost immediately. In fact, Dale was confronting similar difficulties with histamine. But the doubts over histamine were dispelled in 1927 when Dale and chemist Harold Dudley managed to isolate it from the liver and lungs. During this work, Dale had also tested extracts of horse spleen which indicated that it might contain acetylcholine. Although Dale had no idea why the spleen might store acetylcholine, he set about visiting a local slaughterhouse to collect tissue from freshly killed horses and oxen. From this endeavour in 1929, Dale and Dudley managed to obtain seventyone pounds of tissue, from which they extracted one-third of a gram of acetylcholine. It was a tiny amount, but enough to prove that acetylcholine was a natural constituent of biological tissue.

In 1929, Dale along with Harold Dudley managed to extract one-third of a gram of acetylcholine from seventy-one pounds of horse spleen. 
By the early 1930s, most pharmacologists accepted that the parasympathetic branch of the vagus nerve secreted acetylcholine. But, there was little evidence to show that it acted in a similar fashion elsewhere. This situation changed in 1933 when Dale managed to employ Wilhelm Feldberg, who had been forced to leave his university post in Berlin when the Nazi party came to power. In Germany, Feldberg had developed a highly effective way of measuring acetylcholine, which involved recording the contractions of a leech muscle that had been pre-treated with the drug eserine (also known as physostigmine). Remarkably, this increased the muscle's sensitivity to acetylcholine more than a million-fold. And, it was a technique sensitive enough to detect the presence of acetylcholine extracted from the fluids of animals such as cats and dogs.

In 1936, Henry Dale, along with friend Otto Loewi, shared the Nobel

Prize "for their discoveries relating to the chemical transmission of nerve impulses".
Feldberg set about doing this by stimulating a given nerve and then collecting the blood drawn from a nearby vein, hoping that it would reveal tiny amounts of acetylcholine when it was then applied to a leech muscle. In fact, this technique proved so successful over the next three years that Feldberg established the sites of acetylcholine release throughout the peripheral nervous system, producing a spate of some twenty-four papers in the Journal of Physiology. He showed that acetylcholine was secreted at many more places in the nervous system than previously envisaged, including the nerve endings of the parasympathetic nervous system and the synapse at the preganglionic and postganglionic junctions of the sympathetic system. Adding to all these new discoveries, acetylcholine was found to be the neurotransmitter at the neuromuscular junctions where it controlled voluntary muscles. In 1936, Dale and Loewi shared the Nobel Prize "for their discoveries relating to chemical transmission of nerve impulses". Their work has been described by one of the commentators as "the greatest advance in neuroscience of the twentieth century". 


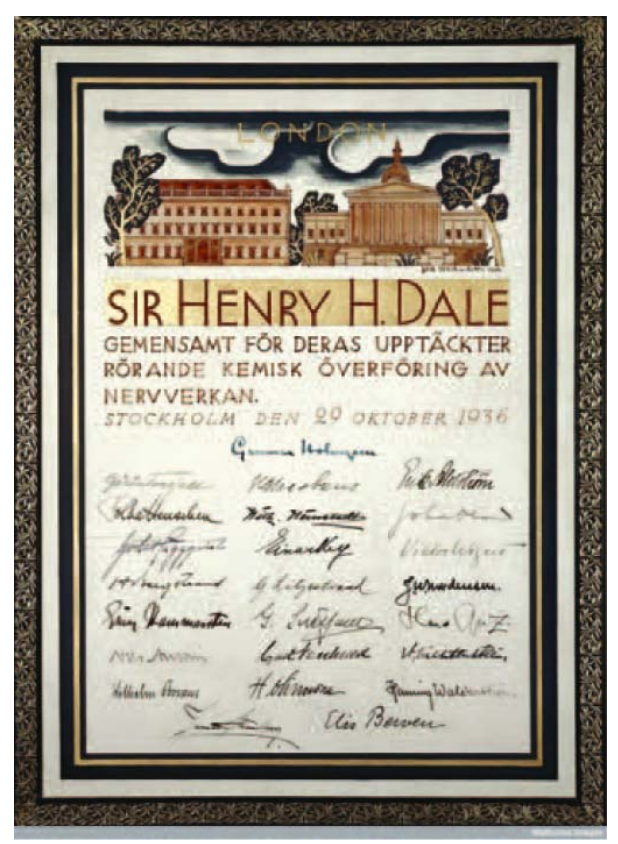

\section{The Soup Versus Sparks Debate}

In his 1936 Nobel Prize acceptance speech, Dale had speculated on the possibility of identifying chemical neurotransmitters in the brain and spinal cord (CNS). However, proving that these substances existed and acted in the peripheral nervous systems had been difficult enough. Confirming chemical neurotransmission in the CNS would be a much more formidable challenge. The problem was not so much as to identifying potential neurotransmitter substances, but also proving that they did not serve some other physiological roles.

An outspoken critic of chemical neurotransmission in the CNS at the time (he favoured electrical transmission instead) was the Australian John Eccles - a renowned neurophysiologist who had been a doctoral student under Charles Sherrington at Oxford after winning a Rhodes scholarship. He had then returned to Australia where he examined the electrophysiological properties of the neuromuscular junction. Later, after moving to the University of Otago, New Zealand, he undertook the first ever intracellular recordings of nerve cells in the CNS in 1950. This advance
Figure 3. The Nobel Prize certificate awarded to Henry Dale in 1936. Source: Wellcome Library, London. 
was made possible by the development of extremely fine glass micropipette electrodes which had a tip diameter of about 0.5 microns (about fifty-thousandths of an inch). Armed with this new technique, Eccles began examining the responses of motor neurons passing out to the quadriceps muscle of the thigh from the spinal cord in anaesthetised cats. When Eccles stimulated a known feedback pathway to these motor neurons, that arose from sensory muscle spindles, with a small electrical current, he found that it caused the resting potential (voltage) inside the cell to temporarily increase slightly.

This appeared to confirm his theory of electrical neurotransmission. A year later, Eccles used a similar procedure to stimulate the sensory pathway originating from the hamstrings of the posterior thigh - that is, the opposing muscle to the quadriceps. This time, however, he obtained an inhibitory postsynaptic potential (IPSP) in the quadriceps motor neuron. In other words, the cell now became more negative for a brief period, making it more resistant to firing. The only reasonable explanation was that both excitatory and inhibitory chemical synapses had to exist. Thus, Eccles was forced to admit that the concept of chemical neurotransmission was correct after all. Later, Dale would write that "a remarkable conversion" had occurred to Eccles, which was similar to "Saul on his way to Damascus when sudden light shone and the scales fell from his eyes". Eccles, who was a devout theist, would probably not have minded the simile.

\section{Dale in Later Life}

Dale remained at the National Institute for Medical Research, where he had become Director), until his retirement in 1942, although he would continue serving on many government committees and play a leading role in numerous learned and medical societies well into old age. Highlights of his numerous awards include a knighthood in 1932, the Royal Society's Copley Medal in 1937, and the Knight's Grand Cross Order of the British Empire in 1948 - an award normally reserved for royalty and heads 
of state. A man who was said to be affable, genial, unstinting in his support of colleagues, Dale was regarded in enormous affection by all who knew him. As President of the Royal Society, a post he held from 1940 to 1945, he espoused the cause of women in science and spoke publicly on a wide range of issues including the need for the scientific establishment to adopt a "new responsibility for the future of mankind". Dale also continued as a trustee for the Wellcome Trust overseeing grant awards for research until his 85 th birthday in 1960 . Even then, he only cut back his work a little, remaining as a scientific advisor until one week before he died in a Cambridge nursing home at the age of 93 years in 1968.

\section{Suggested Reading}

[1] H H Dale, Adventures in Physiology, Pergamon Press Ltd, 1953.

[2] H H Dale, An Autumn Gleaming, Pergamon Press Ltd, 1954.

[3] H W Davenport, Early History of the Concept of Chemical Transmission of the Nerve Impulse, The Physiologist, 34, pp.129-190, 1991.

[4] W Feldberg, Henry Hallett Dale 1875-1968, British Journal of Pharmacology, 35, pp.1-9, 1969.

[5] S Finger, Minds Behind the Brain, Oxford University Press, 2000.

[6] M C Fishman, Sir Henry Hallett Dale and the Acetylcholine Story, Yale Journal of Biology and Medicine, 45, pp.104-118, 1972.

[7] G B Koelle, Henry Hallett Dale 1875-1968, Trends in Pharmacological Sciences, 7, pp.288-289, 1986.

[8] M R Lee, The History or Ergot of Rye (Claviceps purpurea) II: 1900-1940, The Journal of the Royal College of Physicians of Edinburgh, 39, pp.365-369, 2009.

[9] H O Schild, Dale and the Development of Pharmacology, British Journal of Pharmacology, 56, pp.3-7, 1976.

[10] G W Shepherd, Creating Modern Neuroscience, Oxford University Press, 2010.

[11] E M Tansey, Henry Dale and the Discovery of Acetylcholine, Comtes Rendus Biologies, 329, pp.419-425, 2006.

[12] E M Tansey, Henry Dale, Histamine and Anaphylaxis: Reflections on the Role of Chance in the History of Allergy, Studies in History and Philosophy of Biological and Biomedical Sciences, 34, pp.455-472, 2003.

[13] E S Valenstein, The Discovery of Chemical Neurotransmitters, Brain and Cognition, 49, pp.73-95, 2002.

[14] E S Valenstein, The War of the Soup and the Sparks, Columbia University Press, 2005.

[15] A P Wickens, A History of the Brain: From Stone Age Surgery to Modern Neuroscience, Psychology Press, 2014.
Address for Correspondence Dr Andrew Wickens

Department of Psychology University of Central Lancashire Preston, PR1 2HE. Email:

Awickens@uclan.ac.uk 